\title{
Relationship between Demographic Factors, Social Support and Sociocultural Adjustment among International Post Graduate Students in a Malaysian Public University
}

\author{
Maria Chong Abdullah (Ph.D)* \\ Areo Sunday Adebayo \\ Abd Rahim Talib \\ *Corresponding author, Department of Foundations of Education, \\ Faculty of Educational Studies, University Putra Malaysia, mariac@upm.edu.my
}

\author{
Doi:10.5901/jesr.2015.v5n2p87
}

\section{Abstract}

This study examined the relationship between demographic factors, social support and sociocultural adjustment among international post graduate students enrolled in a Malaysian public university. A descriptive correlational research design was utilized to address the research objectives. A total of 150 international students studying in the faculty of educational studies in one of the public university in Malaysia participated in the study. Two research instruments were used to collect the research data. The Multidimensional Scale of perceived social support was used to assess the level of social support perceived by the respondents, while the Socio-cultural Adaptation Scale was used to measure international students' level of sociocultural adjustment. Demographic information such as gender, marital status, and year of study were also collected. Findings show that the respondents have a moderate level of socio-cultural adjustment $(M=2.38)$. The results of independent sample $t$-test show that there were no significant differences in the level sociocultural adjustment based gender (t[150]=-1.50, $p>.05)$, marital status $(F[2,147]=1.18, p=.31)$, and year of study $(F[3,146]=.37, p=.78)$. The result of simple linear regression analysis reveals that social support significantly $(\beta=.27, p=.001 ; R 2=.07)$ predicts students' sociocultural adjustment. Lastly, specific adjustment difficulties reported by the international students were found to be related to making friends, communication, transportation, accommodation, food, job, climate, and time differences. In this study, we can conclude that social support from family, friends and significant others is the key indicator of international student's sociocultural adjustment in Malaysia. Implications of the study and suggestions were also discussed.

Keywords: Sociocultural adjustment; social support; international students.

\section{Introduction}

Moving from one academic environment to another and relocating to a new country to study is becoming an increasingly common occurrence (Brisset, Safdar, Lewis, \& Sabatier, 2010; Yusliza Mohd Yusoff, 2011). Studying in another country can be very exciting for many but it can also be challenging as they have to adapt to new ways of doing things, new culture and meeting people who their way of life and system of educational policy is different from where they are coming from. Living in a new environment trigger a lot changes in one's life including leaving family and friends, meeting new friends and developing networks, learning new social customs and behaviors, experiencing a different climate and different foods, and also adjusting to the language spoken by the people if English is not the first language. Hence, international students experience difficulties in adjusting to a new way of life along with the rigroous academic demands which can put an international student at greater risk than the local students. Problems faced by international students among others include language problem, finacial stress, loneliness, accomodation difficulties, and also problem in adjusting themselves to the culture and believes of their host country etc. Many research and studies have been carried out on campus adjustment of international student in the western world and few studies have been carried out in Asian countries like Malaysia. Therefore, this study intended to contribute to the Malaysian Institution of Higher Learning literature pertaining to this subject.

In Malaysia, the number of international students studying in the Malaysian universities has been increasing throughout the years since 1996 due to various higher education reforms introduced to encourage the entry of international students all around the world into higher education institutions and universities at large. In a bid to make Malaysia an education hub for southeast Asia, the Ministry of Higher Education targets 200,000 international students by 
2020. International students in Malaysia come from about more than 182 different countries all over the world, with majority from Iran, Indonesia, China, Nigeria and Yemen. As they are placed in a new environment which is completely different from where they are from, smooth campus adjustment plays a vital role to ensure the success of these students in completing their studies in Malaysia.

\section{Problem Statement}

Encouraging international students in Malaysia to make a successful campus adjustment is important because many of the international students experience difficulties in adjusting to environment different from theirs. Although, the number of international students on Malaysia campuses continues to increase, only a few numbers of studies have examined international student's adjustment in Malaysia (Yusliza Mohd Yusoff, 2011). Moving from one academic environment to another and relocating to a new country to study is becoming an increasingly common occurrence (Brisset et al., 2010, \& Yusliza Mohd Yusoff, 2011). International students pursuing studies in a foreign country have to overcome the challenges that are related to their adjustment experiences. Some of the challenges include transition and adjustment issues such as the food, weather, language, culture etc. Together with other cultural backgrounds and differences, these conditions exacerbate the difficulties associated with the adjustment process of international students, especially in cross-cultural environments. They are required to deal with the differences between their own cultural values, norms and customs and those of their hosts (Ang \& Liamputtong, 2008, \& Yusliza Mohd Yusoff, 2011). The process of adjustment to these new environments can be a stressful for international students who have the added strain of adjusting to new cultural values, language, and study habits (Li \& Gasser, 2005; Sumer, Poyrazli, \& Grahame, 2008; Yusliza Mohd Yusoff, 2011). Many research and studies have been carried out on campus adjustment of international student in the western world and few studies have been carried out in Malaysia. Therefore, it is necessary to carry out a research to study international student's adjustment in Malaysia. The focus of the current study is to address the adjustment issues and challenges that international students encounter when they come to Malaysia for higher education. The main objective of the study is to examine the relationship between students' demographic factors and social support and international student's sociolcultural adjustment in one of the public universities in Malaysia. Specifically, the study aims to:

(1) idnetify the level of sociocultural adjustment among the international students in university Putra Malaysia,

(2) examine the specific adjustment difficulties experienced by international students in UPM

(3) determine the deferences in sociocultural adjustment based on demographic factors (gender, year of study, marital status) among the international students in a public university, and

(4) determine whether social support is a significant predictor of students' sociocultural adjustment.

\section{Sociocultural Adjustment of International Students}

According to Rathus and Nevid (1986) and Mudhovozi (2012), adjustment is a psychological concept that refers to the behavior that permits people to meet the demands of the environment. Adjustment can be also be viewed as a transitional process that unfold over time as students learn to cope with the exigencies of the university environment (Alsharideh \& Goe, 1998; de Araujo, 2011). In the current study, sociocultural adjustment among international students has been investigated. Sociocultural adjustment refers to cultural specific skills, the ability to negotiate the host culture, or effectively interact with the members of the host culture (Searle \& Ward, 1990; Yusliza Mohd Yusoff \& Shankar, 2010).

Therefore, in this study sociocultural adjustment is the ability of the international students to interact effectively with Malaysians and adapt successfully with the social and the culture of the people in Malaysia. Sociocultural factors are the elements that are related to or pertaining to the combination or interactions of social and cultural habits. Some of these factors are; social taboos, gender roles, religious conservatism etc. Successful acculturation can contribute toward the international students' quality of accademic achievement, productivity and quality of life. As a result of individual diffrences, international students' level of adjustment to a new situation differ. Some may adjust easily while others may find it very difficult to adjust to the circumtances.

\section{Social Support and Adjustment}

According to Cutrona (1990), social support can be defined as behaviours that assist persons who are undergoing stressful life circumstances to cope effectively with the problems they face. However, social support is a factor that appears to improve adjustment, which may provide international students with opportunities to develop an understanding 
of the new culture. Social support is considered within the stress and coping framework and has been found to be an important predictor of psychological adaptation during cross-cultural transitions of international students (Brisset et al., 2010; O'Reilly, Ryan, \& Hickey, 2010; Safdar, Struthers, \& van Oudenhoven, 2009; Ward \& Rana-Deuba, 2000; Yusliza Mohd Yusoff \& Shankar, 2010). Therefore, in this study, social support is the supportive social network received by international students schooling in Malaysia from (family, friends and significant other) to effectively cope with life circumstances or problems they face.

\section{Methodology}

\subsection{Participants}

A descriptive correlation research design was employed to address the objectives of the study. The target population of this study consisted of post-graduate international students from various countries enrolled in various post-graduate programs in a public university in Malaysia. The accessible population is drawn from faculty of Educational Studies with the population of 179 post-graduate international students. Based on Cochran's formula (1977), a sample size of 150 international students was determined for the study. The samples in the study were then selected using a simple random sampling method. 150 post-graduate international students from various countries in the university was randomly selected using fish bowl technique.

\subsection{Instrumentation}

Two research instruments were utilized to collect the research data. The instrument used to assess students' sociocultural adjustment was the Sociocultural Adjustment Scale questionnaire (SCAS) developed by Ward and Kennedy (1999). SCAS has 29 items and was designed to measure the degree to which international students perceived difficulties in understanding the local values and cultures, interacting with the hosts, meeting the demands of daily life, and behaving in a culturally appropriate manner. SCAS contains two constructs namely behavioural adaptation difficulty (22 items) and cognitive adaptation difficulty (7 items) dimensions. Participants will be asked to respond to all the 29items in the questionnaire using a 5-point likert scale ranging from no difficulty (1) to extreme difficulty (5). An openended question was added to identify the specific adjustment difficulties experienced by the respondents. Students' social support was assessed by using the Multidimensional Scale of Perceived Social Support questionnaire (MSPSS) developed by Zimet, Dahlem, and Farley (1988). MSPSS has 12 items. Demographic data of the respondents with regards to their age, gender, marital status and year of study was collected as well.

\section{Results and Discussion}

Results obtained from descriptive and inferential statistical analyses are presented and discussed.

\subsection{Objective 1: Level of Sociocultural Adjustment}

Analyses in Table 1 reveal that the level of overall sociocultural adjustment among international students was in moderatel level $(M=2.38)$. Results also indicate that students experience moderate level in behavioural adjustment difficulties but low in behavioural adjustment difficulty. The moderate level of sociocultural adjustment of international student can be attributed to the ability to learn and understand or see two sides of inter-cultural issues and also the ability to adapt to a changing sociocultural environment. According to Searle and Ward, (1990), Socio-cultural adjustment refers to culture specific skills, the ability to negotiate the host culture, or effectively interact with members of host cultures. Theoretically, the model suggested that sociocultural adjustment can be understood by a social learning context (e.g. socializing with host nationals). 
Table 1. Students' Level of Sociocultural Adjustment

\begin{tabular}{lccc}
\hline Variable & $\boldsymbol{M}$ & SD & Level $^{*}$ \\
\hline Overall Sociocultural & 2.38 & .65 & Moderate \\
Adjustment & 1.86 & .66 & Low \\
Behavioural Adjustment & 2.38 & .65 & Modearate \\
Cognitive Adaptation & &
\end{tabular}

Note: *Low: 1-2.33, Moderate: 2.34-3.66, and High: $3.67-5.00 ; N=150$

\subsection{Objective 2: Specific Adjustment Difficulties Experienced by International Students}

Based on the answer given by the respondents in the open ended question, the specific adjustment difficulties experienced by the respondents can be summarized under the following themes: Making friends, Accommodation, Food, Job, Communication, Transportation, and Climate. The details are as shown in Table 4.

Table 4. Specific Adjustment Difficulties Experienced by Respondents

\begin{tabular}{|l|cl|}
\hline \multicolumn{1}{|c|}{ Theme } & \multicolumn{2}{c|}{ Difficulties } \\
\hline Making friends & - & having hard time making friends with the Malay people \\
\hline Accomodation & - & difficulty to get accommodation, priority given to Iranians \\
\hline Food & - & difficulty to tolerate the big amount of sugar content in food \\
\hline Communication & - & difficult to make friends with the Malay people due to language barrier \\
\hline Transportation & - & difficult to move around without having a car \\
\hline Climate & - & difficult to tolerate the weather which is hot and humid \\
\hline Getting a job & - & hard to get a job to support oneself \\
\hline Time Differences & - & difficult to adjust to the differences in time between Malaysia and student's country \\
\hline
\end{tabular}

\subsection{Objective 3: Differences in Sociocultural Adjustment Based on Gender, Marital Status, and Year of Study}

The findings in Table 2 indicate no significant difference in the sociocultural adjustment based on gender $(t[150]=1.50$, $p>.05)$, marital status $(F[2,147]=1.18, p=.31)$, and year of study $(F[3,146]=.37, p=.78$. This result support previous study conducted by Che Su Mustaffa and Munirah llias (2013) which found no significant difference in the process of adjustment among between male and female international students studying in Northern University of Malaysia. As for marital status, The result of the study shows that there is no difference in sociocultural adjustment regardless of their marital status or whether they are single, married or divorced. Contrary to previous studies on marital status, Poyrazli and Kavanaugh's (2006) study showed that married international students reported experiencing a lower level of social adjustment strain than the single ones. Since these students are married, they do not feel the need to explore other possible relationships, and fulfill their needs for social support at home through their spouses or family members. The finding in this study could be due to the fact that the married and divorced international students are not living with the spouse or loved ones here in Malaysia, which has made them feel homesick and lonely. Married international students whose spouse or child lived with them here in Malaysia might show less difficulty in adjusting themselves to the Malaysian society.

Table 2. Differences in Sociocultural Adjustment Based on Gender, Marital Status, and Year of Study

\begin{tabular}{|c|c|c|c|c|c|c|}
\hline Variable & Gender & $N$ & $M$ & $S D$ & $t$ & sig. \\
\hline \multirow{11}{*}{ Sociocultural Adjustment } & Male & 74 & 2.30 & .63 & -1.50 & .14 \\
\hline & Female & 76 & 2.46 & .66 & & \\
\hline & Marital Status & $N$ & $M$ & $S D$ & $F$ & sig. \\
\hline & Single & 83 & 2.41 & .62 & & \\
\hline & Married & 58 & 2.30 & .69 & 1.18 & .31 \\
\hline & Divorced & 9 & 2.61 & .56 & & \\
\hline & Year of Study & $N$ & $M$ & $S D$ & $F$ & sig. \\
\hline & First Year & 71 & 2.38 & .65 & & \\
\hline & Second Year & 59 & 2.43 & .66 & .37 & .78 \\
\hline & Third Year & 17 & 2.24 & .68 & & \\
\hline & Fourth Year & 3 & 2.41 & .25 & & \\
\hline
\end{tabular}




\subsection{Objective 4: Social Support as Predictor of Student's Sociocultural Adjustment}

The simple linear regression analysis in Table 3 shows that social support significantly predicts sociocultural adjustment among the respondens. Approximately $7.0 \%$ (Adjusted $R^{2}=.07$ ) of the variance in the sociocultural adjustment could be explained by social support. Based on the result, a unit change in social support will bring about the changes of 26 units in sociocultural adjustment. The results of the present study is in line with the claims made by previous research that social support has been found to be an important predictor of psychological adaptation during cross-cultural transitions of international students (Brisset et al., 2010; O'Reilly et al., 2010; Safdar et al., 2009; Sumer et al., 2008; Ward \& RanaDeuba, 2000; Yusliza Mohd Yusoff, 2010). Therefore, in this study, social support is the supportive social network (family, friends and significant other) received by international students schooling in Malaysia. The benefits of having social relationships are crucial for the international students to adjust themselves socioculturally, especially social relationships with friends from Malaysia.

Table 3. Simple Linear Regression Analysis of Social Support as Predictor of Sociocultural Adjustment among International Students

\begin{tabular}{cccccc}
\hline Model & Unstandardized Coefficients & \multicolumn{3}{c}{ Standardized Coefficients } \\
\hline \multirow{2}{*}{ (Constant) } & $\beta$ & Std. Error & Beta & $t$ & Sig. \\
\cline { 2 - 6 } MSPSS $(\mathrm{x})$ & 1.36 & .31 & & 4.460 & .000 \\
& .26 & .08 & .27 & 3.388 & .001 \\
\hline
\end{tabular}

Notes: $\mathrm{DF}=1,148=11.478$, Adjusted $R^{2}=0.072$

\section{Conclusion}

In this study, we can conclude that social support from family, friends and significant others (society) is the key indicator of international student's sociocultural adjustment in Malaysia. Successful and adequate social support from friends, family and significant others would be a big leap for international student's sociocultural adjustment. However, it is important to note that further research into this subject is crucial by taking other aforementioned factors into account.

\section{Implication of the Study}

The evidence from this study suggests that there should be adequate social support provided for international students in Malaysia. Therefore, it is important for universities where international students are enrolled to put emphasis on social support in designing any intervention programmes to promote sociocultural adjustment among international students. Multicultural training workshops should be offered to university staffs such as the teaching staff as well as those who work at the international student office. This will help them to be more aware of the intercultural and intracultural diversity of the students as well as the adjustment process experienced by international students. A friendly and supportive atmosphere should be provided by the university, and host country students should be encouraged to have more interaction with international students. This will probably help the international students to overcome their emotion problems and to adjust themselves better to the local culture. The result of this study may provide useful information for university administrators and government in implementing policies that will help to facilitate sociocultural adjustment of international students in Malaysia

\section{Limitation and Suggestion for Future Research}

Several limitations were discovered in the current study. First, the respondents of this study were from faculty of educational studies alone with the sample population of 150 post-graduate international students. The sample size is small compared to the population of the entire population of post-graduate international students at the selected university. Therefore, this limitation may limit the generalizibility of the results to the entire population of international students in Malaysia. Thus, for future research, it is recommended that the samples to be expanded to all the international student enrolled in the university. And also, it is recommended that other public and private universities and colleges in Malaysia to be included in future research. The current research only investigates certain demographic factors like gender, year of study, and marital status of the respondents. Future research may include other demographic factors such as age and program of study (Doctorate, Master or Diploma) pertaining to international students 
sociocultural adjustment. Furthermore, current study only employed quantitative approach to gain an overview of the issue. Thus, it is suggested that future researchers could employ qualitative approach to overcome the shortcoming of the quantitative research approach. Qualitative data regarding sociocultural adjustment and social support of international students can be obtained by using various techniques such as interviews and observations.

\section{References}

Al-Sharideh, K. A., \& Goe, W. R. (1998). Ethnic communities within the university: An examination of factors influencing the personal adjustment of international students. Research in Higher Education, 39(6), 699-725.

Ang, P. L.D. (2008). "Out of the Circle": international students and the use of university counselling services. Australian Journal of Adult Learning, 48(1), 108-130.

Brisset, C., Safdar, S., Lewis, J. R., \& Sabatier, C. (2010). Psychological and Sociocultural Adaptation of University Students in France: The Case of Vietnamese International Students'. International Journal of Intercultural Relations, 34, 413-426.

Mustaffa, Che Su and Illias, Munirah (2013) Relationship between students adjustment factors and cross cultural adjustment: A survey at the Northern University of Malaysia. Intercultural Communication Studies, 1 (22). pp. 279-300. Retrieved on 3 September 2014, from http://www.uri.edu/iaics/content/2013v22n1/19Che\%20Su\%20Mustaffa\%20\&\%20Munirah\%20llias.pdf

Cochran, W. G. (1977). Sampling techniques (3rd ed.). New York: John Wiley \& Sons.

Cutrona, C. E. (1990). Stress and Social Support-in Search of Optimal Matching. Journal of Social and Clinical Psychology, 9(1), 3-14.

de Araujo, A. A. (2011). Adjustment Issues of International Students Enrolled in American Colleges and Universities: A Review of the Literature. Higher Education Studies, 1(1), 2-8.

Li, A., \& Gasser, M. B. (2005). Predicting Asian international students' sociocultural adjustment: A test of two mediation models. International Journal of Intercultural Relations, 29, 561-576.

Mudhovozi, P. (2012). Social and Academic Adjustment of First Year Universiti Students. J. Soc Sc, 33(2), 251-259.

O'Reilly, A., Ryan, D., \& Hickey, T. (2010). The Psychological Well-being and Sociocultural Adaptation of Short-term International Students in Ireland. Journal of College Student Development, 51 (5): 584-599.

Poyrazli, S., \& Kavanaugh, P. (2006). Marital status, ethnicity, academic achievement, and adjustment strains: the case of graduate international students. College Student Journal, 40(4), 767-780.

Rathus, S. A., \& Nevid, J. S. (1986). Adjustment and growth: The challenges of life (3rd ed.). New York: Holt, Rinehart \& Winston.

Safdar, S., Struthers, W., \& van Oudenhoven, J. P. (2009). Acculturation of Iranians in the United States, the United Kingdom, and the Netherlands. Journal of Cross-Cultural Psychology, 40 (3): 468-491.

Searle, W., \& Ward, C. (1990). The Prediction of Psychological and Sociocultural Adjustment During Cross-cultural Transitions. International Journal of Intercultural Relations. 14 (4): 449-464.

Sumer, S., Poyrazli, S., \& Grahame, K. (2008), Predictors of Depression and Anxiety Among International Students. Journal of Counselling and Development, 86 (4): 429-437.

Ward, C., \& Kennedy, A. (1994). Acculturation strategies, psychological adjustment, and sociocultural competence during cross-cultural transitions. International Journal of Intercultural Relations, 18, 329-343.

Ward, C., \& Rana-Deuba, A. (2000). Home and Host Culture Influences on Sojourner Adjustment. International Journal of Intercultural Relations, 24: 291-306.

Yusliza, Mohd. Yusoff. (2010). Demographic Differences among International Undergraduate Students at a Malaysian Public University. Global Journal of Management and Business Research, (2): 36-41.

Yusliza, Mohd. Yusoff. (2011). International students' adjustment in higher education: Relations between social support, self-efficacy, and socio-cultural adjustment. Australian Journal of Business and Management Research, 1(1), 1-14.

Yusliza, Mohd. Yusoff, \& Shankar, C. (2010). Adjustment in International Students in Malaysian Public University. International Journal of Innovation, Management and Technology, 1 (3): 275-278.

Zimet, G.D., Dahlem, N.W., Zimet, S.G. \& Farley, G.K. (1988). The Multidimensional Scale of Perceived Social Support. Journal of Personality Assessment, 52, 30-41. 